\title{
Should a Manufacturer Encroach on Its Retailer's Operations with Quality Differentiated Products?
}

\author{
Junwu Chai, Huan Chen, Qilin Huang, and Wei Yan \\ School of Management and Economics, University of Electronic Science and Technology of China, Chengdu, China \\ Correspondence should be addressed to Wei Yan; yanwei@uestc.edu.cn
}

Received 26 February 2017; Accepted 27 April 2017; Published 21 June 2017

Academic Editor: Gabriella Bretti

Copyright (C) 2017 Junwu Chai et al. This is an open access article distributed under the Creative Commons Attribution License, which permits unrestricted use, distribution, and reproduction in any medium, provided the original work is properly cited.

\begin{abstract}
Despite the fact that manufacturers are progressively encroaching into the retail market by selling products that differ in quality from the products that are already on the market, this issue has received little attention in the literature on dual-channel supply chains. We fill this gap by first considering that a manufacturer sells higher- (lower-) quality products through its own direct channel, whereas all lower- (higher-) quality products are distributed by an independent retailer, and then comparing our equilibrium outcomes with those in the literature of the manufacturer who distributes homogeneous products through both channels. Our results show that, compared to selling lower-quality products directly or offering homogeneous products through both channels, an effort by the manufacturer that is too aggressive in its attempt to encroach on the retail market (i.e., selling higher-quality products directly) not only decreases the retailer's profits but also reduces the manufacturer's own profitability. Furthermore, we find that, compared with offering homogeneous products through both channels, selling lower-quality products directly is always beneficial for the retailer but hurts consumers.
\end{abstract}

\section{Introduction}

Over the past few decades, a growing number of manufacturers have encroached on the retail market with different forms, including manufacturer outlet, company owned stores, catalog sales, online sales, and telemarketing $[1,2]$. According to one survey, roughly $42 \%$ of the top suppliers in a variety of industries have encroached on retailer market by selling products directly [3]. Such examples are prevalent across many industries including but not limited to PCs industry (such as Apple, IBM, and Cisco), cosmetics makers (e.g., Estee Lauder), beverage and food manufacturers (Budweiser Beer, Coca Cola, and Campbell Soup), sports goods producers (e.g., Nike), and electronics suppliers (e.g., PalmOne, Samsung, and Sony) [4].

A side effect of this trend is that such encroachment not only changes traditional supply chains into dual-channel supply chains but also threatens the profitability of existing retailers and creates channel conflicts [5]. To mitigate channel conflicts and increase all parties' profitability, many researchers have provided different ways, like pricing policy
[6] and service level $[7,8]$ for channel coordination. However, an increasing number of manufacturers have adopted a strategy of selling products that differ in quality from the existing products on the market through different channels $[9,10]$ to alleviate the competition. For instance, in the U.S. PC market, Dell and Toshiba have opted to build PCs exclusively, which are generally of higher quality, for retailers, such as Best Buy and Circuit City [11]. Chinese electronics manufacturer Lenovo recently began offering differentiated products for online and offline platforms in several developing countries, such as China and India [12]. Likewise, German sportswear and apparel maker Puma is looking to balance its e-commerce platform and brick-and-mortar stores: "We cannot overlook e-commerce and hence we are looking to have a product differentiation strategy starting this year's autumn-winter collection," said Ganguly, Managing Director, Puma India. "This differentiation will reduce channel conflict" [13].

However, this rationale falls flat when considering the many brand manufacturers who succeed in supplementing their preexisting retail channels with a manufacturer-owned channel by selling homogeneous products. For example, 
although Apple offers different versions of the Mac, iPhone and iPad, it sells exactly homogeneous products through both its e-channel and brick-and-mortar stores. Samsung operates similar websites for a variety of its products, including PCs, digital cameras, tablets/E-books, and printers, that are identical to the products in its brick-and-mortar stores.

The question that this raises is whether a manufacturer should encroach on the retail market by selling differentquality products with softened competition or providing homogeneous products with higher competition (i.e., which strategies provide higher sales and profits for the manufacturer under what type of market conditions?) and whether the retailer prefers to interact with a manufacturer who encroaches on the retail market by selling different-quality products or by offering homogeneous products (i.e., which strategies would be profitable for the retailer under what type of market conditions?). To answer these strategic questions, we need to understand the rationale that would lead all parties to choose their best response to strategies of selling different-quality products in a dual-channel supply chain (such as PC manufacturers in the US and Puma in India) or offering homogeneous products through both channels (such as Apple and Samsung).

In this paper, we start by developing two basic models, in which a manufacturer sells higher- (lower-) quality products through its own direct channel, whereas all lower- (higher-) quality products are distributed by an independent retailer. Our intent is to characterize the strategic behaviour of all parties using quality differentiation strategies in a dualchannel supply chain and its effects on all parties' profits. We then examine the implications of quality differentiation strategies for manufacturers and/or retailers by comparing our equilibrium outcomes with those in the literature, particularly in [2], which is based on a manufacturer who distributes homogeneous products through both channels.

Despite the fact that a progressively greater number of manufacturers are encroaching on the retail market by selling quality differentiated products, little is known about its managerial implications on the market structure, firms' performance, and consumers welfare. Therefore, from a managerial perspective, this paper shows how the strategies of selling quality differentiated products in a dual-channel supply chain, in which the manufacturer is both a supplier and a competitor of the retailer, create strategic consequences that extend beyond obtaining a competitive advantage from the horizontal competition at the manufacturer's or retailer's level.

The common wisdom is that a manufacturer offering quality differentiated products through two channels prefers to sell its higher-quality products through the direct channel. In contrast, our results show that, compared to selling lowerquality products directly or offering homogeneous products through both channels, an effort by the manufacturer that is too aggressive in its attempt to encroach on the retail market (i.e., selling higher-quality products directly) not only decreases retailer profit but also hurts manufacturer profitability. This result may approximate the way, despite extant theoretical predictions, in which PC makers are more likely to encroach on the retail market by selling lower-quality or homogeneous products directly on the U.S. and China markets. Furthermore, we find that, compared with offering homogeneous products through both channels, selling lower-quality products directly is always beneficial for the retailer but usually hurts consumer. An observation implies that to obtain higher profits, intermediaries, such as Home Depot and Wal-Mart, may not need to worry about supplier encroachment, particularly when the encroachment entails selling lower-quality products directly because such an encroachment can always shift consumer surplus to them.

The remainder of the paper is organized as follows. Section 2 reviews the related literature and explains our contributions in more detail. Section 3 describes our two basic models and reports our main findings. Section 4 concludes this paper.

\section{Relevant Literature}

To the best of our knowledge, there is little theoretical literature studying the different-quality strategies in a dualchannel supply chain. However, extant literature not only provides some guidance in terms of how to approach this problem but also provides a benchmark in terms of the substantive findings. At first, there is a large literature on the channels of distribution associated with vertical product differentiation models, where products differ in the quality and consumers have different willingness to pay for products quality (see, for example, Balasubramanian [14]; Desai and Purohit [15]; Ferrer and Swaminathan [16]; Yan [17]; Yan et al. [18]). However, only Yan [17] uses this vertical product differentiation framework to address channel coordination in a multichannel supply chain. In their case, the author focuses on the strategic roles played by differentiated branding and profit sharing in a multichannel manufacturer-retailer supply chain. However, he assumes that all cross-price sensitivities (denoted by $f$ ), which reflect the intensity of the channel competition, are symmetric and normalizes them to zero in a divided market. That means the demands in different channels are independent when the manufacturer adopts differentiated branding strategy. In contrast to these studies, in our model, we focus on the different-quality strategies when the manufacturer encroaches on the retailer's market and pay attention to its managerial implications for all parties' profits. In addition, we address the issue of cannibalization problem between the products from different channels, which relate to the degree of consumers' taste for quality.

Another related stream of literature studies the research on the competition between both channels when a manufacturer encroaches on the retail market (see, for example, Chiang et al. [19]; Tsay and Agrawal [20]; Arya et al. [2]; Xiong et al. [21]). In particular, Chiang et al. [19] identify conditions under which, in order to offset the advantage its retail arm secures, the manufacturer sets a lower wholesale price in the encroachment setting than in the no-encroachment setting. They do not, however, model vertical differentiation between lower- and higher-quality products. Arya et al.s [2] objective is similar to Chiang et al. [19]. However, their main finding is that the retailer can benefit from encroachment even when encroachment admits no synergies and does not facilitate 
product differentiation or price discrimination. Evidently, our aim is quite different from theirs. For example, whether to sell different-quality products through different channels is not a decision in Arya et al. [2]. Furthermore, we examine the implications of different-quality strategies to manufacturers and/or retailers, by comparing the equilibrium outcomes of two models with those in the related literature, especially with those in Arya et al. [2].

Our work is particularly closely related to Ha et al. [22] but is different from theirs in several important aspects. First, they assume that the products quality can be designed in the process of production to examine how the manufacturers choice of product quality depends on its strategies of encroachment. Said differently, they address supplier encroachment problems and quality choice strategies in operations domain. In contrast, like Yan [17] and Ferrer and Swaminathan [16], we assume that product quality is exogenous and investigate how this parameter creates strategic issues that considerably impact on encroachment problems and all parties profitability in marketing domain. Second, as mentioned earlier, we examine the implications of differentquality strategies in marketing domain, and thus, unlike $\mathrm{Ha}$ et al. [22], our game-theoretic model nests Arya et al. [2] as a special case when quality differentiation level reduces to zero and thus generalizes it to the different-quality setting. In addition, contrary to Ha et al.s [22] results, our analysis shows that, rather than encroaching into retail market with high-quality product, the manufacturer clearly should prefer the strategy of providing lower-quality products directly or offering homogeneous products through both channels. An observation approximates the way in which PC makers are more likely to encroach on the retail market by providing lower-quality or homogeneous products directly on the U.S. and China markets.

There are two other research streams indirectly related to our research. The first one uses the vertical product differentiation framework to consider entry deterrence problems and quality choice strategies in operations domain (see, for example, Vandenbosch and Weinberg [23]; Desai [24]; Noh and Moschini [25]; Lauga and Ofek [26]; Zeithammer and Thomadsen [27]). In this stream, products quality can be designed in the process of production to examine how the incumbent's choice of product quality depends on the threat strategies of entrant. Consequently, they ignored the role played by a downstream agent (retailer or dealer) in a distribution channel. Moreover, they do not pay any attention to the setting of manufacturers encroaching on retailer's market by taking different-quality strategies. A related second stream uses the vertical product differentiation framework to deal with the cannibalization problems between new and remanufactured products (see, for example, Ferrer and Swaminathan [16]; Bulmuş et al. [28]; Bulmus et al. [29]; Xiong and Yan [30]). Their primary purpose is to understand how the remanufactured products potentially cannibalize the sales of new versions of the same product. We, in contrast, focus on the cannibalization problem between lower- and higher-quality products from different channels when the manufacturer encroaches on the retail market.
Last, in economics and industrial management, horizontal differentiation models are used to describe a product differentiation strategy, when the product's horizontal feature is different from consumers' ideal preferences. The horizontal differentiation literature (see, for example, Xia and Rajagopalan [31] and references therein) is mainly based on Hotelling's [32] model in which two firms compete in location and price within a linear city. However, most of this literature studies a setting where two retailers compete with each other. Instead, we develop a vertical model, in which, when offered at the same price, all consumers choose to purchase the same one, that of higher-quality. Moreover, we analyze the interaction between a manufacturer and a retailer when the manufacturer encroaches on the retail market by selling products directly.

Our overall contribution is therefore twofold. First, we address an aspect mostly ignored by extant research in the marketing area: the fact that manufacturers have a potential flexibility to sell different-quality products through different channels when they encroach on the retail market. Second, although there is a considerable body of research on differentquality strategies, little is known about how the interaction between a manufacturer and a retailer in a dual-channel supply chain can be affected by this issue. Said differently, we provide an alternative and somewhat complementary approach to consider how different channel structures for marketing different-quality products impact all players' performance.

\section{Model Description}

3.1. Model Development. Consider two basic models with different-quality strategies, in which a manufacturer sells higher- (lower-) quality products through its own direct channel, while all lower- (higher-) quality products are distributed by an independent retailer (see also Figure 1).

We adopt the assumptions of Arya et al. [2] regarding the sequence of the game between the manufacturer and the retailer. That is, the manufacturer announces the wholesale price to the retailer, who then responds by determining the optimal units of selling. The manufacturer then encroaches into the retail market by choosing the units to be sold through the manufacturer-owned direct channel. Our assumptions regarding the manufacturer, retailer, consumer preferences, and decision making framework are as follows.

3.1.1. Manufacturer Strategies. The manufacturer is a profit maximizer who chooses the best wholesale price, $w$, and units to sell through a direct channel, $q_{M}$, to maximize profit. To enable a focus on product marketing and market structures, like Arya et al. [2], we assume that the marginal cost of selling through the direct channel is $c_{d}=c>0$.

3.1.2. Retailer Strategies. If the manufacturer sets the wholesale price, the retailer must choose the optimal quantities that it intends to sell to maximize profit. Suppose that the unit marketing cost in the retail channel is and normalized to zero (i.e., $c_{R}=0$ ). Recall that the marginal cost of selling through the direct channel is $c_{d}=c>0$. Such a difference in 


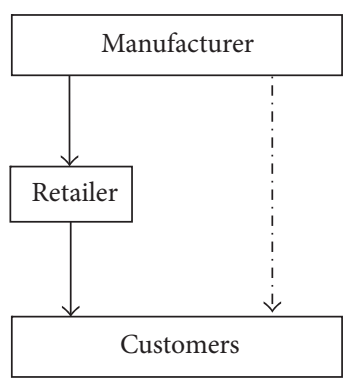

Lower-quality products

(a) Model $H$ (encroaching with higher-quality products)

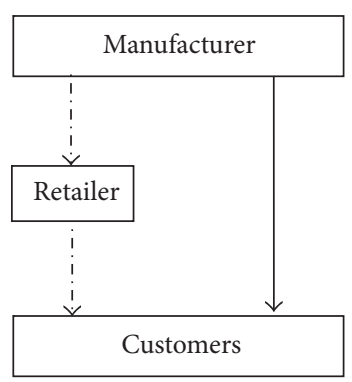

Higher-quality products

(b) Model L (encroaching with lower-quality products)

Figure 1: The two basic models.

marginal marketing costs reflects certain key characteristics when the manufacturer encroaches on the retail market by direct selling: on the one hand, as in Arya et al. [2], a difference in marginal marketing costs shows that the retailer has an advantage in the channels of distribution. On the other hand, as in Lutz [33], a difference in marginal marketing costs reflects the ability of the incumbent to deter entry into the market.

3.1.3. Consumers. The size of the consumer population is assumed to be constant over time and is normalized to a size of 1 . To capture consumers who differ in their willingness to pay, suppose that consumers are heterogeneous in the utility that they derive from consumption and are characterized by their type $\theta \in[0,1]$, which is heterogeneous and uniformly distributed in $[0,1]$. That is, we assume that consumer type $\theta$ has a valuation of $\theta$ for a higher-quality product, which is heterogeneous and uniformly distributed in $[0,1]$. To capture every consumer who prefers a higher-quality product, we use the parameter $\gamma \in(0,1)$ to present the willingness to pay ratio of a lower-quality product to a higher-quality product. Consumer type $\theta$ thus has a valuation of $\gamma \theta$ for a lowerquality product. As in Desai and Purohit [34] and Ferrer and Swaminathan [16], we derive the inverse demand functions from the consumer utility functions as follows:

$$
\begin{aligned}
& p_{h}=1-q_{h}-\gamma q_{l}, \\
& p_{l}=\gamma\left(1-q_{h}-q_{l}\right),
\end{aligned}
$$

where $p_{h}$ and $p_{l}$ are the prices of higher-quality and lowerquality products, respectively, and $q_{h}$ and $q_{l}$ are the total units of higher-quality and lower-quality products, respectively.

3.2. Model Analysis. In this section, we first look at the strategic behaviour of all parties using differentiation strategies in a dual-channel supply chain and its effects on all parties' profits. And then we examine the implications of different-quality strategies for manufacturers and/or retailers. More specifically, we first consider the two basic models with different-quality strategies, in which a manufacturer sells higher- (lower-) quality products through its own direct channel, while all lower- (higher-) quality products are distributed by the independent retailer, respectively. And then we examine the implications of differentiation strategies for manufacturers and/or retailers by comparing our equilibrium outcomes with those in the literature, particularly in Arya et al. [2], which is based on a manufacturer who distributes homogeneous products through both channels.

3.2.1. Encroaching with Higher-Quality Products. We begin our analysis by considering Model $H$, in which the manufacturer encroaches on the retail market by selling higherquality products directly, while all lower-quality products are distributed by an independent retailer. In this analysis, we use uppercase $\Pi_{i}$ (lowercase $\pi_{i}$ ) to represent the manufacturer's (retailer's) profit under model $i$, and $i=H, L$, and $N$ refers to Model $H$ (encroaching with higher-quality products), Model $L$ (encroaching with lower-quality products) and Model $N$ (no-encroachment setting), respectively.

We perform the ensuing analysis using backward induction because consumers' expectations are rational, meaning that a subgame perfect Nash equilibrium can be determined. Thus, when encroaching with higher-quality products (Model $H$ ), the manufacturer's problem is

$$
\max _{q_{h}} \Pi_{H}\left(q_{l}, q_{h}, w\right)=\max _{q_{h}}\left(w q_{l}+p_{h} q_{h}-c q_{h}\right),
$$

where the first two terms are the revenue from wholesaling and selling, respectively, and the last term is the cost of selling products directly.

Given the wholesale price $(w)$ and anticipating the manufacturer's response $q_{h}^{*}$, the retailer's problem is

$$
\max _{q_{l}} \pi_{H}\left(q_{l}, q_{h}, w\right)=\max _{q_{l}}\left(p_{l} q_{l}-w q_{l}\right) .
$$

When the manufacturer determines the wholesale price $(w)$, it anticipates this quantity decision $q_{l}^{*}$ by the retailer. Substituting $q_{h}^{*}$ and $q_{l}^{*}$ into (2) permits the creation of a representation of the manufacturer's profit as a function of $w$. 


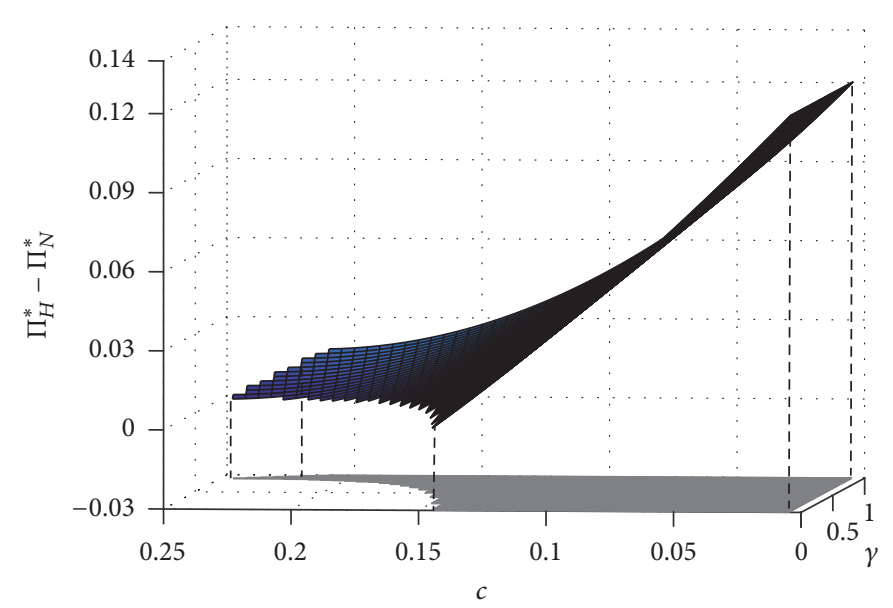

(a) $\Pi_{H}^{*}-\Pi_{N}^{*}$

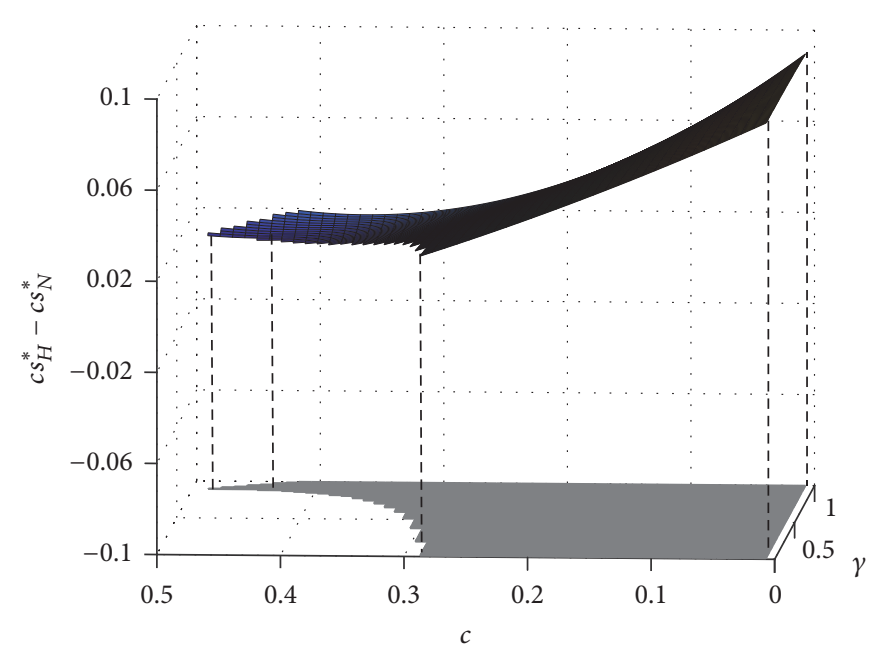

(c) $c s_{H}^{*}-c s_{N}^{*}$

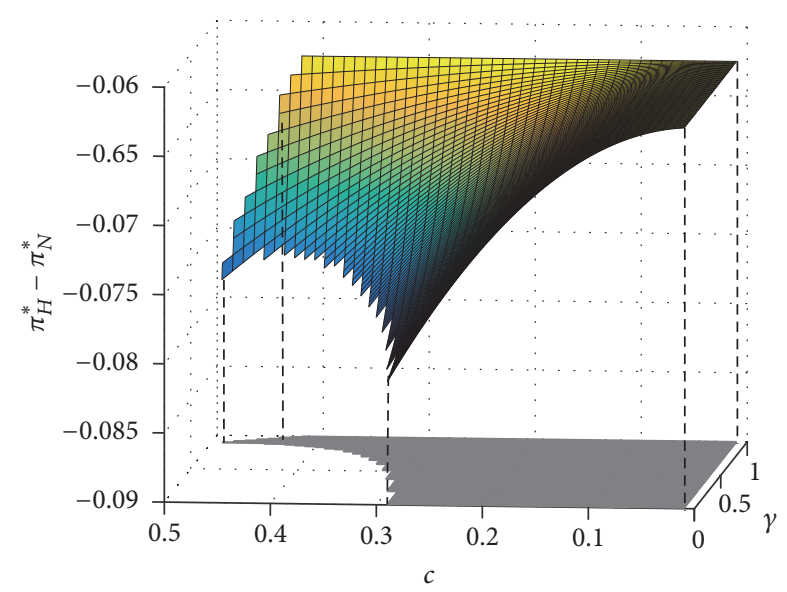

(b) $\pi_{H}^{*}-\pi_{N}^{*}$

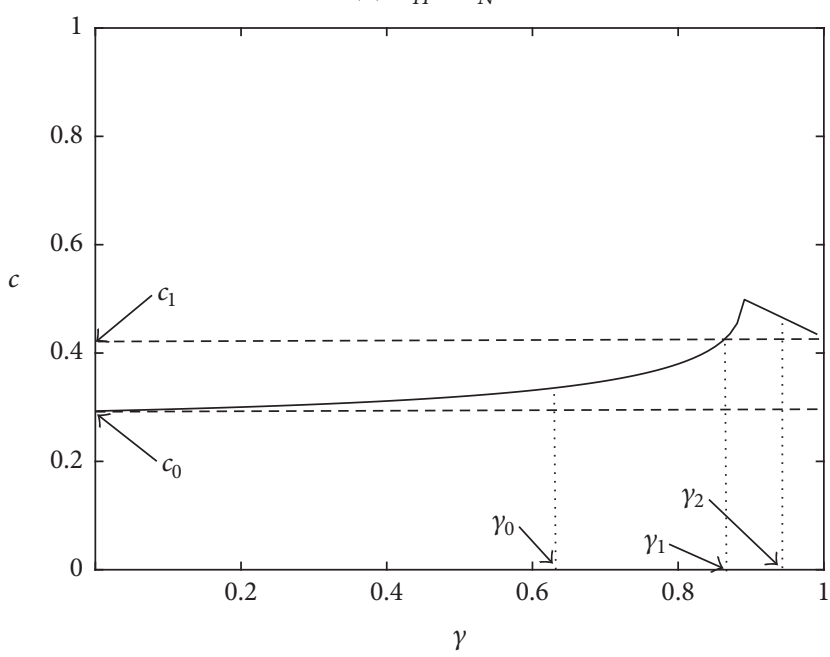

(d) The horizontal projection of key conditions

Figure 2: Key conditions of Model $H$.

Maximizing the expression yields $w^{*}$. The equilibrium outcomes of both parties under Model $H$ are summarized in Lemma 1.

Lemma 1. In Model $H$, the equilibrium quantities, wholesale prices, and profits can be summarized as follows:

$$
\begin{aligned}
q_{h}^{*} & =\frac{5 \gamma-8-3 \gamma c+8 c}{10 \gamma-16} ; \\
q_{l}^{*} & =\frac{2 c}{8-5 \gamma} ; \\
w^{*} & =\frac{\gamma(8-\gamma c-5 \gamma)}{2(8-5 \gamma)} ; \\
\Pi_{H}^{*} & =\frac{\gamma c^{2}+5 \gamma-10 \gamma c-8+16 c-8 c^{2}}{20 \gamma-32} ; \\
\pi_{H}^{*} & =\frac{2 \gamma c^{2}(2-\gamma)}{(8-5 \gamma)^{2}} ; \\
c s_{H}^{*} & =\frac{(5 \gamma-8-3 \gamma c+8 c)^{2}+16 c^{2} \gamma}{8(8-5 \gamma)^{2}} .
\end{aligned}
$$

Intuitively, the manufacturer can limit the competition from the retail channel and bolster its competitive position in two ways: encroaching into the retail market by selling products directly and/or increasing the wholesale price to the retailer. By comparing the equilibrium outcomes in Lemma 1 with those in a no-encroachment setting (Model N) (all equilibrium outcomes of Model $N$ are listed in the Appendix), we summarize our findings in the following proposition (see, Figure 2(a)) (for clarity, all proofs are provided in the Appendix).

Proposition 2. Iff $(16-2 \gamma) c^{2}+(20 \gamma-32) c+8-5 \gamma>0$, the manufacturer's profit under encroachment by selling higherquality products is greater than that in a no-encroachment setting (i.e., $\Pi_{H}^{*}>\Pi_{N}^{*}$ ); that is, the manufacturer has a willingness to encroach on the retail market in this case.

First, Proposition 2 shows (see Figure 2(d)) that if the manufacturer's retail cost disadvantage is not too pronounced, the manufacturer will encroach on the retail market. Otherwise, the manufacturer will abandon the strategy of encroachment. Proposition 2 is consistent with the results of Arya et al. [2] and Xiong et al. [21]. Obviously, encroachment 
would be more fruitful for the manufacturer to increase the profit for two reasons. On the one hand, by controlling the distribution of the direct channel, a manufacturer can gain from selling via both channels. Furthermore, profit margins can be earned on the higher-quality products and thus higher profits from consumers directly. On the other hand, encroachment endows the manufacturer with a mechanism to control the selling price in the retail market and consequently motivates her to reduce the wholesale price. The combination of these two effects mitigates double marginalization (all of the channel members independently seek to maximize their own profit, resulting in higher retail prices and lower sales quantities and profits than in a vertically integrated channel [35]) and can benefit both the manufacturer and retailer when the latter has a significant efficiency advantage in the retail process [36].

Second, Proposition 2 indicates (see also Figure 2(d)) that the manufacturer's profitability also depends on the vertical differentiation $(\gamma)$ between both products, which means a cannibalization effect for the manufacturer/retailer who faces consumers who differ in their quality valuations. More specifically, when the retailer's cost advantage is low, that is, $c<$ $c_{0}$, the manufacturer will overlook the cannibalization effect between lower- and higher-quality products and encroach on the retail market at any consumers' pay ratio $\gamma$. However, when the retailer's cost advantage is moderate (i.e., $c_{0}<c<$ $c_{1}$ ), which means that marketing products through the retail channel is a more effective method than direct selling, the manufacturer will not encroach on the retail market when consumers' pay ratio $\gamma$ is too low (e.g., $\gamma<\gamma_{0}$ ), preventing some consumers who would have purchased lower-quality products through the retail channel from switching to higherquality products in the direct channel. When the retailer's cost advantage increases (i.e., $c_{1}<c$ ), marketing products through the retail channel is more effective than direct selling. To protect the profitability of the retail channel, the manufacturer will not encroach on the retail market when consumers' pay ratio $\gamma$ is too low (e.g., $\gamma<\gamma_{1}$ ). However, the manufacturer will not encroach on the retail market when consumers' pay ratio $\gamma$ is too high (e.g., $\gamma>\gamma_{2}$ ) because the retailer's cost advantage is sufficiently high and the cannibalization problem between lower- and higherquality products is severe.

Although many researchers (e.g., Chiang et al. [19]; Arya et al. [2]; Xiong et al. [21]) state that the retailer may benefit from the reduced wholesale price when the manufacturer encroaches on the market by selling homogeneous products, little is known about how the reduced wholesale price under encroachment with differentiated products affects the retailer's profit. In particular, we find that although a lower wholesale price accompanies encroachment, the retailer is always worse off when confronting the manufacturer's encroachment by selling higher-quality products directly (see Figure 2(b)).

Proposition 3. (i) The retailer's profit under the encroachment with higher-quality products is always lower than that under no-encroachment settings (i.e., $\pi_{H}^{*}<\pi_{N}^{*}$ ). (ii) Consumers benefit from the manufacturer's encroachment. That is, all consumers benefit when a manufacturer sells higher-quality products directly (i.e., $c s_{H}^{*}>c s_{N}^{*}$ ).

Not surprisingly, (see Figure 2(c)), from a consumer welfare perspective, the manufacturer's encroachment increases consumer surplus. To understand this, first note that although all products differ in quality and consumers have different levels of willingness to pay for differentiated products, the introduction of a direct channel creates a cannibalization problem between lower- and higher-quality products. Said differently, the manufacturer's encroachment will increase retail competition and thus consumer surplus due to positive demand externalities. Additionally, the lower wholesale price is accompanied by the manufacturer's encroachment, which provides direct gains for the retailer and increases the availability of products in the retail channel, creating a higher level of consumer surplus.

Because the retailer may benefit from the supplier's encroachment due to the lower wholesale price that accompanies encroachment [2], we examine a setting in which the manufacturer encroaches on the retail market by selling higher-quality products through a direct channel. We show that as Proposition 3(i) indicates, although the manufacturer always sets a lower wholesale price to the retailer, an effort by the manufacturer to encroach on the retail market (i.e., selling higher-quality products directly) that is too aggressive is always detrimental to the retailer.

3.2.2. Encroaching with Lower-Quality Products. In the second scenario, the manufacturer encroaches on the retail market by selling lower-quality products directly. Thus, in Model $L$, the manufacturer optimizes

$$
\max _{q_{l}} \Pi_{L}\left(q_{l}, q_{h}, w\right)=\max _{q_{l}}\left(w q_{h}+p_{l} q_{l}-c q_{l}\right) .
$$

Given the optimal quantities $\left(q_{l}^{*}\right)$ and anticipating the manufacturer's response $w$, the retailer's problem is

$$
\max _{q_{h}} \pi_{H}\left(q_{l}, q_{h}, w\right)=\max _{q_{h}}\left(p_{h} q_{h}-w q_{h}\right) .
$$

Given the optimal quantities $\left(q_{l}^{*}\right)$ and the retailer's response $q_{h}^{*}$, the manufacturer's problem is

$$
\max _{w} \Pi_{L}\left(q_{l}, q_{h}, w\right)=\max _{w}\left(w q_{h}+p_{l} q_{l}-c q_{l}\right) .
$$

We can then use standard backward induction to summarize the equilibrium quantities, wholesale prices, and profits under Model $L$, as summarized in Lemma 4.

Lemma 4. In Model $L$, the equilibrium quantities, wholesale prices, and profits can be summarized as follows:

$$
\begin{aligned}
& q_{l}^{*}=\frac{3 \gamma^{2}-3 \gamma c-6 \gamma+8 c}{10 \gamma^{2}-16 \gamma} ; \\
& q_{h}^{*}=\frac{2(1-\gamma+c)}{8-5 \gamma}
\end{aligned}
$$




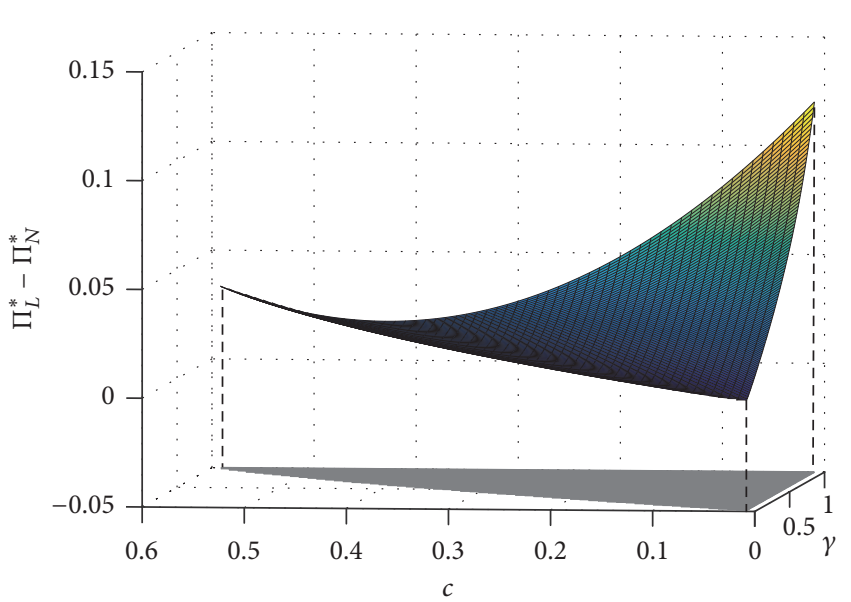

(a) $\Pi_{L}^{*}-\Pi_{N}^{*}$

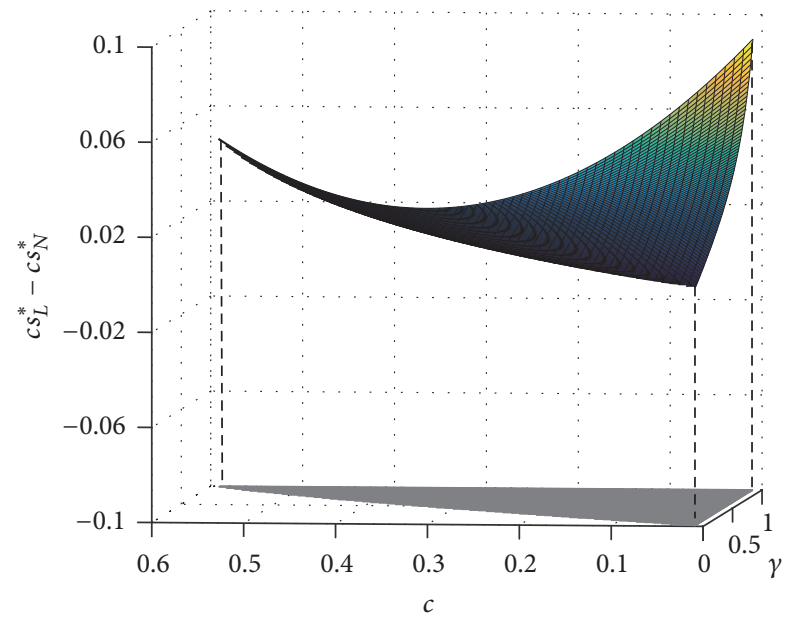

(c) $c s_{L}^{*}-c s_{N}^{*}$

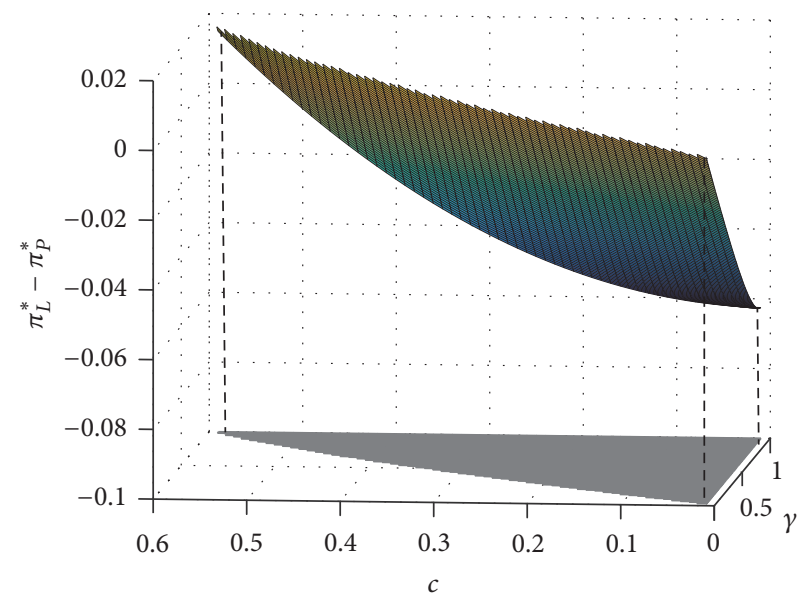

(b) $\pi_{L}^{*}-\pi_{N}^{*}$

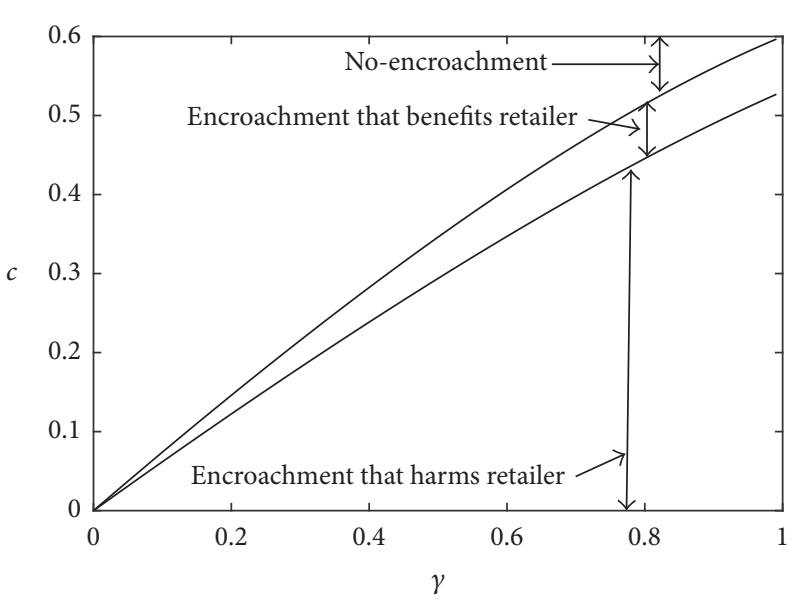

(d) The horizontal projection of key conditions

FIgUre 3: Key conditions of Model $L$.

$$
\begin{aligned}
& w^{*}=\frac{8+\gamma^{2}-6 \gamma-\gamma c}{2(8-5 \gamma)} ; \\
& \Pi_{L}^{*}=\frac{8 c^{2}+4 \gamma+2 \gamma^{2} c-\gamma^{3}-8 \gamma c-\gamma c^{2}}{4 \gamma(8-5 \gamma)} ; \\
& \pi_{L}^{*}=\frac{2(1+c-\gamma)^{2}(2-\gamma)}{(8-5 \gamma)^{2}} ; \\
& c s_{L}^{*}=\frac{\gamma\left(3 \gamma^{2}-3 \gamma c-6 \gamma+8 c\right)^{2}+4(2-2 \gamma-2 c)^{2}}{8(8-5 \gamma)^{2}} .
\end{aligned}
$$

Similar to the analysis of Model $H$, we first focus on the question of how selling lower-quality products directly affects the manufacturer's performance. We obtain the following proposition (see Figure 3(a)).

Proposition 5. Iff $6 \gamma-3 \gamma^{2}+(3 \gamma-8) c>0$, the manufacturer encroaches on the retail market by selling lower-quality products directly. Such an encroachment is beneficial for the manufacturer (i.e., $\Pi_{L}^{*}>\Pi_{N}^{*}$ ).

We then focus on the question of how the encroachment of selling lower-quality products directly affects the retailer's performance and consumers' welfare, as summarized in the following proposition (see Figures 3(b) and 3(c)).

Proposition 6. (i) When $32(1+c-\gamma)^{2}(2-\gamma)-(8-5 \gamma)^{2}>0$, the retailer benefits from the manufacturer's encroachment with lower-quality products (i.e., $\pi_{L}^{*}>\pi_{N}^{*}$ ). Otherwise, the retailer's profit is lower than that would be in a no-encroachment setting (i.e., $\pi_{L}^{*}<\pi_{N}^{*}$ ).

(ii) Consumers always benefit from the encroachment of selling lower-quality products directly (i.e., $c s_{L}^{*}>c s_{N}^{*}$ ).

Contrary to Proposition 3, Proposition 6(i) shows that when the manufacturer encroaches on the retail market by selling lower-quality products directly, the retailer may benefit from the manufacturer's encroachment. Note that, in Models $H$ and $L$, if both lower-quality products and higherquality products are offered at the same price, all consumers 


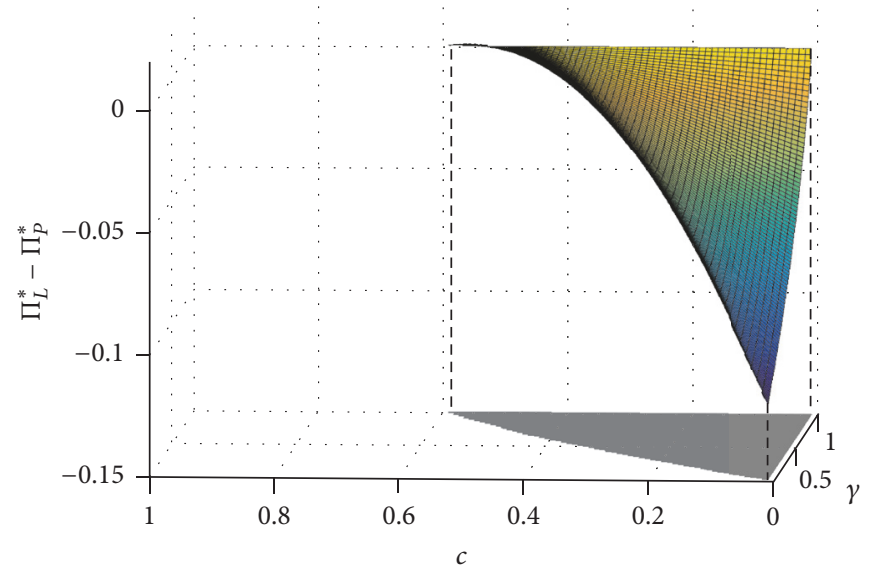

(a) $\Pi_{L}^{*}-\Pi_{P}^{*}$

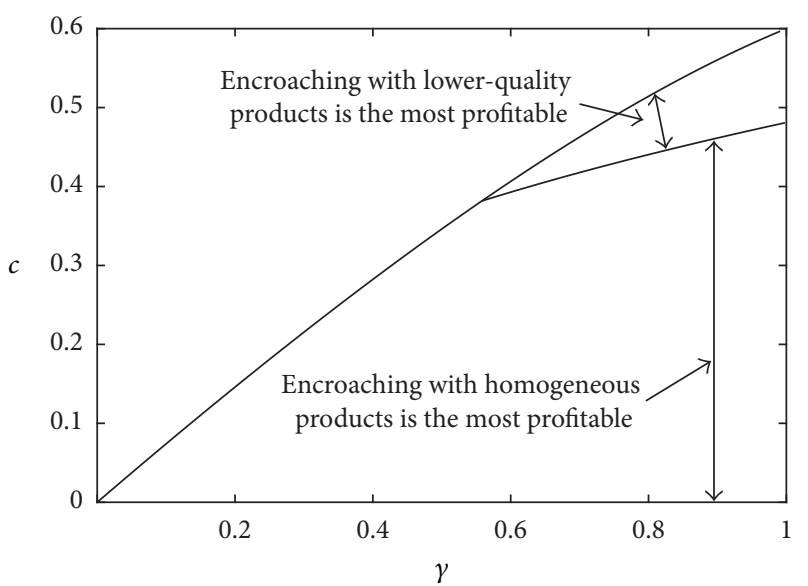

(b) The horizontal projection of key conditions

FigURE 4: Key conditions of the three models.

will purchase the higher-quality product. That is, the competition between the higher- and lower-quality products is asymmetric: in terms of customer perceptions, higher-quality products are perfect substitutes for lower-quality products, whereas lower-quality products are imperfect substitutes for higher-quality products. Thus, when the manufacturer encroaches on the retail market by selling lower-quality products directly, customer prefers to choose the product sold by traditional retail channel and the retailer suffers a smaller loss in sales than that in Model $H$, where the manufacturer encroaches on the retail market by selling higher-quality products directly. Thus, the retailer may benefit from the manufacturer's encroachment in Model $L$ but may suffer from the manufacturer's encroachment in Model $H$. Figure 3(d) illustrates the key conditions of encroachment from selling lower-quality products directly.

Additionally, Proposition 6(i) highlights an interesting result consistent with the results from Arya et al. [2], who found that the retailer benefits because encroachment induces the encroaching supplier to reduce the wholesale price to stabilize the retailer's demand for the manufacturer's wholesale product (P651). However, note that the models of Arya et al. [2] do not facilitate product differentiation or price discrimination.

3.2.3. Implications of Different-Quality Strategies. Our analysis thus far has described the manufacturer's and retailer's strategies in Models $H$ and $L$, respectively. We now examine the implications of selling differentiated products to manufacturers, retailers, and consumers. To address this issue, we should compare the equilibrium in Models $H$ and $L$ with that in the literature, particularly in Arya et al. [2], which assumes that all homogeneous products are distributed through both channels. To compare the equilibrium from both models to the case in Arya et al. [2], let us use the subscript $\mathrm{P}$ to distinguish their result for the situation in which the manufacturer sells homogeneous products through both channels (all equilibrium outcomes of Model $P$ are listed in the Appendix).
As before, we first pay attention to the implications to the manufacturer (see Figure 4).

Proposition 7. When $\gamma^{2}-12 \gamma+24 \gamma c+(24-35 \gamma) c^{2}>0$, the manufacturer is better off in Model L than it is in two other cases (i.e., Models $H$ and P). Otherwise, selling homogeneous products creates the highest profits.

Proposition 7 shows that when $3 \gamma^{2}-12 \gamma+24 \gamma c+(24-$ $35 \gamma) c^{2}>0$, it is optimal for the manufacturer to encroach on the retailer's market by selling lower-quality products through direct channels. Otherwise, like the result of Arya et al. [2], the manufacturer benefits more from encroachment by selling homogeneous products through both channels. That is, a too aggressive effort by the manufacturer to encroach on the retail market (i.e., selling a higher-quality product directly) is always a suboptimal strategy for the manufacturer because it yields a lower profit for the manufacturer than the profits derived in Models $L$ and $P$. That is to say, when customer's willingness to pay ratio of a lower-quality product to a higher-quality product and the marginal selling cost meet some equivalent relations, to achieve higher profit, a manufacturer had better to adopt quality differentiated strategy to encroach on the retail market.

A good illustration is provided by the PC industry, where manufacturers are likely to choose one of two encroachment strategies: some manufacturers in the U.S. PC market, such as Dell and Toshiba, build PCs exclusively, which are generally of higher quality, for intermediaries, such as Best Buy and Circuit City [11]. A similar trend can be found in the Chinese PC market, where an increasing number of manufacturers build lower-quality PCs and distribute them through a direct channel [37]. However, many other manufacturers offer homogeneous products through both channels. For example, although Apple offers different versions of the Mac, iPhone, and iPad, it offers homogeneous products through both its e-channel and brick-and-mortar stores. Samsung operates websites similar to its brick-and-mortar stores through which it sells homogeneous products. 
Because selling a higher-quality product through a direct channel is always a suboptimal strategy for a manufacturer who acts as a Stackelberg leader, we do not need to reexamine the optimal strategy and performance of the retailer and consumers in Model $H$. Comparing retailer profits and consumers' welfare under Model $L$ to those in Arya et al. [2] leads to the following proposition.

Proposition 8. (i) The retailer is always better off under the manufacturer's encroachment with selling lower-quality products directly, that is, $\pi_{L}^{*}>\pi_{P}^{*}$.

(ii) Consumers benefit from the manufacturer's encroachment with sale of homogeneous products directly. That is, $c s_{P}^{*}>$ $c s_{L}^{*}$.

Obviously, the retailer is always better off with the encroachment of selling lower-quality products directly for two reasons. First, in terms of customer perception, lowerquality products are imperfect substitutes for the products sold through the retail channel. And customer is always reasonable to choose products with relatively higher quality. As a result, the retailer faces less aggressive competition from the manufacturer's encroachment of selling lowerquality products directly than that from selling homogeneous products directly. Second, firms differentiate their products to avoid ruinous price competition and some form of monopoly rent [38]. Therefore, the retailer can benefit more with the manufacturer's encroachment of selling lower-quality products directly than in selling homogeneous products directly. Additionally, Proposition 8(ii) reveals that when consumers have a different willingness to pay for product quality, compared to selling homogeneous products directly, the manufacturer's encroachment of selling lower-quality products directly can shift some consumer surplus to the retailer and/or manufacturer.

Based on Propositions 7 and 8, we conclude that, compared to offering homogeneous products through both channels, selling lower-quality products directly always benefits the retailer and is only sometimes profitable for the manufacturer. This result has two important implications. First, under certain conditions, offering different products (i.e., selling differentiated products) through different channels can alleviate channel conflict. On the one hand, encroaching on the retailer market by differentiated products equips manufacturer with larger sales from end customer to enhance its profitability and creates another stream of profit. On the other hand, a lower wholesale price can be significant for increasing retailer's profit, consequently, which can reduce the retail price and benefit the customer. Thus, achieving channel coordination results in increased profits for all parties, a conclusion supported by Bucklin et al. [9], Lee et al. [10], and Yan [17].

Many retailers may resent the manufacturer's encroachment; for example, in 1999, Home Depot issued a Godfatheresque directive to more than 1,000 suppliers asking them to stop selling products directly [39]. However, our above result implies that to obtain higher profits, intermediaries, such as Home Depot and Wal-Mart, may not need to worry about supplier encroachment, particularly when the encroachment entails selling lower-quality products directly because such an encroachment can always shift consumer surplus to them.

It is of interest to compare the results in Propositions 7 and 8 with the results of Mussa and Rosen's [40] model, in which a firm interacts directly with consumers who choose the product that fetches them the highest value from the offered product line, indicating that product line price discrimination can shift consumer surplus to the firm. We first compare the retailer in Model L to Mussa and Rosen's [40] firm, the difference being that the retailer in Model $L$, who sells higher-quality products in the retail channel, depends on a strategic upstream agent (the manufacturer). From this perspective, we find that although the manufacturer sells lower-quality products through the direct channel, product line price discrimination can shift some consumer surplus to the retailer. Thus, inserting a strategic upstream agent into Mussa and Rosen's [40] model does not alter their result.

Alternatively, we compare the manufacturer in Model $L$ to the firm in Mussa and Rosen's [40] model, the difference being that our manufacturer must interact with a downstream intermediary when all higher-quality products are distributed in the retail channel. From this research angle, we find that when endogenizing a strategic downstream agent (retailer) to Mussa and Rosen's [40] model, the result changes. In particular, when $3 \gamma^{2}-12 \gamma+24 \gamma c+(24-35 \gamma) c^{2}<0$, the manufacturer can benefit from selling homogeneous products rather than from adopting price discrimination between higher- and lower-quality products (a detailed explanation for the reversal can be found in Proposition 7).

\section{Conclusion}

An increasing number of manufacturers have faced a dilemma today: if they do not sell their products directly, consumers will go to the competitors who do, while if they sell products directly, their distributors and dealers will desert them and only carry products from manufacturers who do not as in Wilson [41]. A workable solution to this problem is to sell different products through different channels. As a result, a growing number of manufacturers have adopted a strategy of selling products that differ in quality from the existing products on the market.

Despite the fact that a progressively greater number of manufacturers are encroaching on the retail market by selling differentiated products, this issue has received little attention in the literature on dual-channel supply chains. We therefore develop two models in which a manufacturer sells higher(lower-) quality products through its own direct channel, whereas all lower- (higher-) quality products are distributed by an independent retailer. And then we examine the implications of differentiation strategies for manufacturers and/or retailers by comparing our equilibrium outcomes with those in the literature, particularly in Arya et al. [2], which is based on a manufacturer who distributes homogeneous products through both channels.

Our analysis shows that, compared to selling lowerquality products directly or offering homogeneous products through both channels, an effort by the manufacturer that is too aggressive in its attempt to encroach on the retail 
market (i.e., selling higher-quality products directly) not only decreases retailer profit but also hurts manufacturer own profitability. This result may help explain what happened when the now-defunct company Compaq encroached on the market and provides valuable insights into the impacts of product line price discrimination on profitability for all parties in a dual-channel supply chain. Another important finding in this paper is that, under certain conditions, selling lower-quality products directly can alleviate channel conflict and increase all parties' profits. An observation is consistent with the trends in the U.S. and China PC markets, in which a growing number of PC makers have opted to build PCs exclusively, which are generally higher quality, for certain intermediaries.

We acknowledge some limitations of this paper. First, we view the degree of different quality between both products is determined exogenously, an assumption that, although common in the literature of marketing (e.g., Purohit [42]; Desai and Purohit [15]; Yan et al. [18]), endogenizing the degree of different quality between both products in the current models is a laudatory task. In addition, we assume that consumers show no preference between the direct channel and the retail channel, whereas, in reality, consumers may exhibit different preferences over different distribution channels. We hope this research could open a potentially interesting avenue of research: incorporation into the model's demand functions of consumer preferences for services provided by different products in different distributions. Besides the above, we assume that the manufacturer is limited to a linear wholesale price. Although it is common in reality and standard in literature, it is also of interest to understand the implication of encroachment when a manufacturer can use a more complex pricing mechanism. At last, in practice, there are also many manufacturers that distribute products with different quality through different retailers rather than their own direct echannel or even adopt different brands from traditional retailer and direct online channel to encroach on retailer. Considering the two settings where the manufacturer sells quality differentiated products by two retailers or competes with retailer by different brand is a worthy subject for future research.

\section{Appendix}

Notice. Although all parameters and variables must satisfy nonnegativity constraints, we only make them explicit when some constraint is binding. In addition, all equilibrium outcomes of no-encroachment setting (Model $N$ ) and selling homogeneous products setting (Model $P$ ) are exactly the same as that in settings of "the no-encroachment" and "the encroachment" in Arya et al. [2], after the simplification of $a=b=1$. That is, $\Pi_{N}^{*}=1 / 8, \pi_{N}^{*}=1 / 16, c s_{N}^{*}=1 / 32$; $\Pi_{p}^{*}=\left(3-6 c+7 c^{2}\right) / 12, \pi_{p}^{*}=2 c^{2} / 9, c s_{p}^{*}=(3-c)^{2} / 72$.

\section{A. Proof of Lemma 1}

Plugging (1) into the manufacturer's profit (2) and solving the first-order condition yields $q_{h}^{*}=\left(1-\gamma q_{l}-c\right) / 2$.
After substituting (1) and $q_{h}^{*}$, the problem of the retailer is given by $\max _{q_{l}}\left(q_{l}\left(\gamma+\gamma^{2} q_{l}+\gamma c-2 \gamma q_{l}-2 w\right) / 2\right)$; by applying FOCs to it with respect to $q_{l}^{*}$, we can obtain $q_{l}^{*}=(\gamma+\gamma c-$ $2 w) / 2 \gamma(2-\gamma)$.

Plugging (1), $q_{h}^{*}$, and $q_{l}^{*}$ into the manufacturer's profit, because the objective function is concave in $w$, we can easily show that the optimal $w^{*}=\gamma(8-\gamma c-5 \gamma) / 2(8-5 \gamma)$.

Substituting $w^{*}$ into $q_{h}^{*}, q_{l}^{*},(2)$, and (3), the consumer surplus provides the equilibrium outcomes in Model $H$.

\section{B. Proof of Proposition 2}

To prove $\Pi_{H}^{*}>\Pi_{N}^{*}$, we have to show that $\left(\gamma c^{2}+5 \gamma-10 \gamma c-\right.$ $\left.8+16 c-8 c^{2}\right) /(20 \gamma-32)>1 / 8$.

After simplification, we have that $(16-2 \gamma) c^{2}+(20 \gamma-32) c+$ $8-5 \gamma>0$.

That is to say, for any $c$ and $\gamma$, when $(16-2 \gamma) c^{2}+(20 \gamma-$ 32) $c+8-5 \gamma>0, \Pi_{H}^{*}>\Pi_{N}^{*}$ always holds.

\section{Proof of Proposition 3}

(i) To prove $\pi_{H}^{*}<\pi_{N}^{*}$, we have to show that $2 \gamma c^{2}(2-\gamma) /(8-$ $5 \gamma)^{2}<1 / 16$.

After simplification, we have that $32 \gamma(\gamma-2 \gamma) c^{2}+64-80 \gamma+$ $25 \gamma^{2}>0$, which is true by the condition in Proposition 2 .

That is to say, for any $c$ and $\gamma$, when $(16-2 \gamma) c^{2}+(20 \gamma-$ 32) $c+8-5 \gamma>0, \pi_{H}^{*}<\pi_{N}^{*}$ always holds.

(ii) To prove $c s_{H}^{*}>c s_{N}^{*}$, we have to show that $((5 \gamma-8-$ $\left.3 \gamma c+8 c)^{2}+16 c^{2} \gamma\right) / 8(8-5 \gamma)^{2}>1 / 32$.

After simplification, we have that $\left(512 \gamma-512-120 \gamma^{2}\right) c^{2}+$ $\left(36 \gamma^{2}-128 \gamma+256\right) c+75 \gamma^{2}+192-240 \gamma>0$, which is true by the condition in Proposition 2.

That is to say, for any $c$ and $\gamma$, when $(16-2 \gamma) c^{2}+(20 \gamma-$ 32) $c+8-5 \gamma>0, c s_{H}^{*}>c s_{N}^{*}$ always holds.

\section{Proof of Lemma 4}

Plugging (1) into the manufacturer's profit (5) and solving the first-order condition yield $q_{l}^{*}=\left(\gamma-\gamma q_{h}-c\right) / 2 \gamma$.

After substituting (1) and $q_{l}^{*}$, the problem of the retailer is given by $\max _{q_{l}}\left(q_{h}\left(2-\gamma+\gamma q_{h}+c-2 q_{h}-2 w\right) / 2\right)$; by applying FOCs to it with respect to $q_{l}^{*}$, we can obtain $q_{h}^{*}=(2-\gamma+c-$ $2 w) / 2(2-\gamma)$.

Plugging (1), $q_{l}^{*}$, and $q_{h}^{*}$ into the manufacturer's profit, because the objective function is concave in $w$, we can easily show that the optimal $w^{*}=\left(8+\gamma^{2}-6 \gamma-\gamma c\right) / 2(8-5 \gamma)$. Substituting $w^{*}$ into $q_{l}^{*}, q_{h}^{*},(5)$, and (6), the consumer surplus provides the equilibrium outcome in Model $L$.

\section{E. Proof of Proposition 5}

To prove $\Pi_{L}^{*}>\Pi_{N}^{*}$, we have to show that $\left(8 c^{2}+4 \gamma+2 \gamma^{2} c-\right.$ $\left.\gamma^{3}-8 \gamma c-\gamma c^{2}\right) / 4 \gamma(8-5 \gamma)>1 / 8$.

After simplification, we have that $2(8-\gamma) c^{2}+(4 \gamma-16) \gamma c+$ $5 \gamma^{2}-2 \gamma^{3}>0$, which is true by the condition for $q_{l}^{*}>0$ (i.e., $\left.6 \gamma-3 \gamma^{2}+(3 \gamma-8) c>0\right)$. 
That is to say, for any $c$ and $\gamma$, when $6 \gamma-3 \gamma^{2}+(3 \gamma-8) c>0$, $\Pi_{L}^{*}>\Pi_{N}^{*}$ always holds.

\section{F. Proof of Proposition 6}

(i) $\pi_{L}^{*}-\pi_{N}^{*}=2(1+c-r)^{2}(2-r) /(8-5 \gamma)^{2}-1 / 8$; after simplification, we find that there exists a critical value $f(\gamma, c)=32(1+c-\gamma)^{2}(2-\gamma)-(8-5 \gamma)^{2}$, when $f(\gamma, c)$, $\pi_{L}^{*}-\pi_{N}^{*}>0$; otherwise, $\pi_{L}^{*}-\pi_{N}^{*}<0$.

That is to say, for any $c$ and $\gamma$, when $32(1+c-\gamma)^{2}(2-\gamma)-$ $(8-5 \gamma)^{2}, \pi_{L}^{*}>\pi_{N}^{*}$ holds; otherwise, the opposite is true.

(ii) To prove $c s_{L}^{*}>c s_{N}^{*}$, we have to show that $\left(\gamma\left(3 \gamma^{2}-\right.\right.$ $\left.3 \gamma c-6 \gamma+8 c)^{2}+4(2-2 \gamma-2 c)^{2}\right) / 8(8-5 \gamma)^{2}>1 / 32$.

After simplification, we have that $\left(36 \gamma^{2}+256-128 \gamma\right) c^{2}+$ $\left(208 \gamma^{2}-256 \gamma-72 \gamma^{3}\right) c+36 \gamma^{4}+96 \gamma^{2}-105 \gamma^{3}>0$, which is true by the condition for $q_{l}^{*}>0$ (i.e., $6 \gamma-3 \gamma^{2}+(3 \gamma-8) c>0$ ).

That is to say, for any $c$ and, when $6 \gamma-3 \gamma^{2}+(3 \gamma-8) c>0$, $c s_{L}^{*}>c s_{N}^{*}$ always holds.

\section{G. Proof of Proposition 7}

$\Pi_{H}^{*}-\Pi_{P}^{*}=8 c^{2}(1-\gamma) / 3(5 \gamma-8)<0$; that is, $\Pi_{H}^{*}<\Pi_{P}^{*}$.

$\Pi_{L}^{*}-\Pi_{P}^{*}=\left(35 \gamma^{2} c^{2}+24 \gamma c+24 c^{2}+15 \gamma^{2}-12 \gamma-59 \gamma c^{2}-3 \gamma^{3}-\right.$ $\left.24 \gamma^{2} c\right) / 12 \gamma(8-5 \gamma)$; we find that there exists a critical value $f(\gamma, c)=3 \gamma^{2}-12 \gamma+24 \gamma c+(24-35 \gamma) c^{2}$, when $f(\gamma, c)>0$, $\Pi_{L}^{*}-\Pi_{P}^{*}>0$; otherwise, $\Pi_{L}^{*}-\Pi_{P}^{*}<0$.

That is to say, for any $c$ and $\gamma$, when $3 \gamma^{2}-12 \gamma+24 \gamma c+$ $(24-35 \gamma) c^{2}$ and when $f(\gamma, c)>0, \Pi_{L}^{*}>\Pi_{P}^{*}>\Pi_{H}^{*}$; that is, the manufacturer is better off in Model $L$ than in two other cases; otherwise, $\Pi_{P}^{*}>\Pi_{L}^{*}>\Pi_{H}^{*}$; that is, a selling homogeneous products strategy has highest profits.

\section{H. Proof of Proposition 8}

Note that since selling a higher-quality product through the direct channel is always a suboptimal strategy for a manufacturer who acts as a Stackelberg leader, we need not reexamine the optimal strategy and performance of the retailer and consumers in Model $H$ in the proof of Proposition 8.

(i) To prove $\pi_{L}^{*}>\pi_{P}^{*}$, we have to show that $2(1+c-r)^{2}(2-$ $r) /(8-5 \gamma)^{2}>2 c^{2} / 9$.

After simplification, we have that $\left(71 \gamma-46-25 \gamma^{2}\right) c^{2}+$ $\left(36-54 \gamma+18 \gamma^{2}\right) c+18+36 \gamma^{2}-9 \gamma^{3}-45 \gamma>0$, which is true by the condition for $q_{l}^{*}>0$ (i.e., $6 \gamma-3 \gamma^{2}+(3 \gamma-8) c>0$ ).

That is to say, for any $c$ and, when $6 \gamma-3 \gamma^{2}+(3 \gamma-8) c>0$, $\pi_{L}^{*}>\pi_{P}^{*}$ always holds.

(ii) To prove $c s_{P}^{*}>c s_{L}^{*}$, we have to show that $\left(\gamma\left(3 \gamma^{2}-3 \gamma c-\right.\right.$ $\left.6 \gamma+8 c)^{2}+4(2-2 \gamma-2 c)^{2}\right) / 8(8-5 \gamma)^{2}<(3-c)^{2} / 72$.

After simplification, we have that $\left(352 \gamma+25 \gamma^{3}-161 \gamma^{2}-\right.$ 576) $c^{2}+\left(192 \gamma+12 \gamma^{3}+12 \gamma^{2}\right) c+405 \gamma^{3}-756 \gamma^{2}-81 \gamma^{4}+432 \gamma>0$, which is true by the condition for $q_{l}^{*}>0$ (i.e., $6 \gamma-3 \gamma^{2}+(3 \gamma-$ $8)(>0)$.

That is to say, for any $c$ and, when $6 \gamma-3 \gamma^{2}+(3 \gamma-8) c>0$, $c s_{P}^{*}>c s_{L}^{*}$ always holds.

\section{Conflicts of Interest}

The authors declare that they have no conflicts of interest.

\section{Acknowledgments}

The authors thank the National Natural Science Foundation of China (71472026, 71672020), Humanities and Social Sciences Foundation for Young Scholars of China's Ministry of Education (15YJC630154), Fundamental Research Funds for the Central Universities (ZYGX2015KYQD080), and the Electronic Commerce and Modern Logistics Research Center Program, Key Research Base of Humanities and Social Science, Sichuan Provincial Education Department (DSWL169) for supporting this research.

\section{References}

[1] J. Tannenbaum, "Franchisees resist poaching via software, kiosks, Internet," Wall Street Journal, 1995, (October 30).

[2] A. Arya, B. Mittendorf, and D. E. M. Sappington, "The bright side of supplier encroachment," Marketing Science, vol. 26, no. 5, pp. 651-659, 2007.

[3] B. Tedeschi, "Compressed data; big companies go slowly in devising net strategy," The New York Times, 2000, (March 27).

[4] L. Hsiao and Y.-J. Chen, "Strategic motive for introducing internet channels in a supply chain," Production and Operations Management, vol. 23, no. 1, pp. 36-47, 2014.

[5] K. Cattani, W. Gilland, H. S. Heese, and J. Swaminathan, "Boiling frogs: pricing strategies for a manufacturer adding a direct channel that competes with the traditional channel," Production and Operations Management, vol. 15, no. 1, pp. 4056, 2006.

[6] N. M. Modak, S. Panda, and S. Sana S, "Pricing policy and coordination for a distribution channel with manufacturer suggested retail price," International Journal of Systems Science Operations \& Logistics, vol. 3, no. 2, pp. 92-101, 2016.

[7] B. C. Giri and B. R. Sarker, "Coordinating a two-echelon supply chain under production disruption when retailers compete with price and service level," Operational Research, vol. 16, no. 1, pp. 71-88, 2016.

[8] X. Qin, Q. Su, S. H. Huang, U. J. Wiersma, and M. Liu, “Service quality coordination contracts for online shopping service supply chain with competing service providers: integrating fairness and individual rationality," Operational Research, pp. 128, 2017.

[9] C. B. Bucklin, P. A. Thomas-Graham, and E. A. Webster, "Channel conflict: when is it dangerous?" The McKinsey Quarterly, vol. 3, pp. 36-43, 1997.

[10] Y. Lee, Z. Lee, and K. R. T. Larsen, "Coping with Internet channel conflict," Communications of the ACM, vol. 46, no. 7, pp. 137-142, 2003.

[11] C. Lawton, "Tweaking the standard-issue PC," Wall Street Journal (Eastern Edition), 2007, (June 14), D1.

[12] P. Vishant, "Lenovo to offer differentiated products in online and offline channels," (accessed date: 12.06.2015), http://indianonlineseller.com/2014/10/lenovo-to-offer-differentiated-products-in-online-and-offline-channels/.

[13] A. Law, "Puma to differentiate products for e-commece, brickand-mortar platforms," http://www.thehindubusinessline.com/ 
companies/puma-to-differentiate-products-for-ecomm-brickandmortar-platforms/article7252326.ece.

[14] S. Balasubramanian, "Mail versus mall: a strategic analysis of competition between direct marketers and conventional retailers," Marketing Science, vol. 17, no. 3, pp. 181-195, 1998.

[15] P. S. Desai and D. Purohit, "Competition in durable goods markets: the strategic consequences of leasing and selling," Marketing Science, vol. 18, no. 1, pp. 42-58, 1999.

[16] G. Ferrer and J. M. Swaminathan, "Managing new and differentiated remanufactured products," European Journal of Operational Research, vol. 203, no. 2, pp. 370-379, 2010.

[17] R. Yan, "Managing channel coordination in a multi-channel manufacturer-retailer supply chain," Industrial Marketing Management, vol. 40, no. 4, pp. 636-642, 2011.

[18] W. Yan, Y. Xiong, Z. Xiong, and N. Guo, "Bricks vs. clicks: which is better for marketing remanufactured products?" European Journal of Operational Research, vol. 242, no. 2, pp. 434-444, 2015.

[19] W. K. Chiang, D. Chhajed, and J. D. Hess, "Direct marketing, indirect profits: a strategic analysis of dual-channel supplychain design," Management Science, vol. 49, no. 1, pp. 1-20, 2003.

[20] A. A. Tsay and N. Agrawal, "Channel conflict and coordination in the E-commerce age," Production and Operations Management, vol. 13, no. 1, pp. 93-110, 2004.

[21] Y. Xiong, W. Yan, K. Fernandes, Z.-K. Xiong, and N. Guo, "Bricks vs. clicks': the impact of manufacturer encroachment with a dealer leasing and selling of durable goods," European Journal of Operational Research, vol. 217, no. 1, pp. 75-83, 2012.

[22] A. Ha, X. Long, and J. Nasiry, "Quality in supply chain encroachment," Manufacturing and Service Operations Management, vol. 18, no. 2, pp. 280-298, 2016.

[23] M. B. Vandenbosch and C. B. Weinberg, "Product and price competition in a two-dimensional vertical differentiation model," Marketing Science, vol. 14, no. 2, pp. 224-249, 1995.

[24] P. S. Desai, "Quality segmentation in spatial markets: when does cannibalization affect product line design?" Marketing Science, vol. 20, no. 3, pp. 265-283, 2001.

[25] Y.-H. Noh and G. Moschini, "Vertical product differentiation, entry-deterrence strategies, and entry qualities," Review of Industrial Organization, vol. 29, no. 3, pp. 227-252, 2006.

[26] D. O. Lauga and E. Ofek, "Product positioning in a twodimensional vertical differentiation model: the role of quality costs," Marketing Science, vol. 30, no. 5, pp. 903-923, 2011.

[27] R. Zeithammer and R. Thomadsen, "Vertical differentiation with variety-seeking consumers," Management Science, vol. 59, no. 2, pp. 390-401, 2013.

[28] S. C. Bulmuş, S. X. Zhu, and R. Teunter, "Capacity and production decisions under a remanufacturing strategy," International Journal of Production Economics, vol. 145, no. 1, pp. 359-370, 2013.

[29] S. C. Bulmus, S. X. Zhu, and R. Teunter, "Competition for cores in remanufacturing," European Journal of Operational Research, vol. 233, no. 1, pp. 105-113, 2014.

[30] Y. Xiong and W. Yan, "Implications of channel structure for marketing remanufactured products," European Journal of Industrial Engineering, vol. 10, no. 1, pp. 126-144, 2016.

[31] N. Xia and S. Rajagopalan, "Standard vs. custom products: Variety, lead time, and price competition," Marketing Science, vol. 28, no. 5, pp. 887-900, 2009.

[32] H. Hotelling, "Stability in competition," The Economic Journal, vol. 39, no. 153 , pp. 41-57, 1929.
[33] S. Lutz, "Vertical product differentiation and entry deterrence," Journal of Economics/Zeitschrift fur Nationalokonomie, vol. 65, no. 1, pp. 79-102, 1997.

[34] P. Desai and D. Purohit, "Leasing and selling: optimal marketing strategies for a durable goods firm," Management Science, vol. 44, no. 11, pp. S19-S34, 1998.

[35] J. J. Spengler, "Vertical integration and antitrust policy," The Journal of Political Economy, vol. 58, no. 4, pp. 347-352, 1950.

[36] Z. Li, S. M. Gilbert, and G. Lai, "Supplier encroachment under asymmetric information," Management Science, vol. 60, no. 2, pp. 449-462, 2014.

[37] Xinhuanet.com, "Focusing on the qulity diffferentitation strategy between online and offline channels," 2014, (accessed date: 08.06.2015), http://news.xinhuanet.com/tech/2014-06/23/ c126657478.htm.

[38] S. P. Anderson, A. de Palma, and J.-F. Thisse, Discrete Choice Theory of Product Differentiation, MIT Press, Cambridge, Mass, USA, 1992.

[39] K. Brooker, "E-rivals seem to have Home Depot awfully nervous," Fortune, vol. 140, no. 4, pp. 28-29, 1999.

[40] M. Mussa and S. Rosen, "Monopoly and product quality," Journal of Economic Theory, vol. 18, no. 2, pp. 301-317, 1978.

[41] R. Wilson, "Manufacturer's dilemma: to sell or not to sell directly," Web Commerce Today, 1998, (May 15).

[42] D. Purohit, "Marketing channels and the durable goods monopolist: renting versus selling reconsidered," Journal of Economics \& Management Strategy, vol. 4, no. 1, pp. 69-84, 1995. 


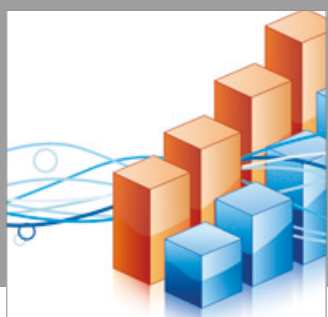

Advances in

Operations Research

vatersals

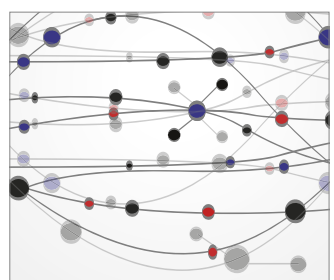

\section{The Scientific} World Journal
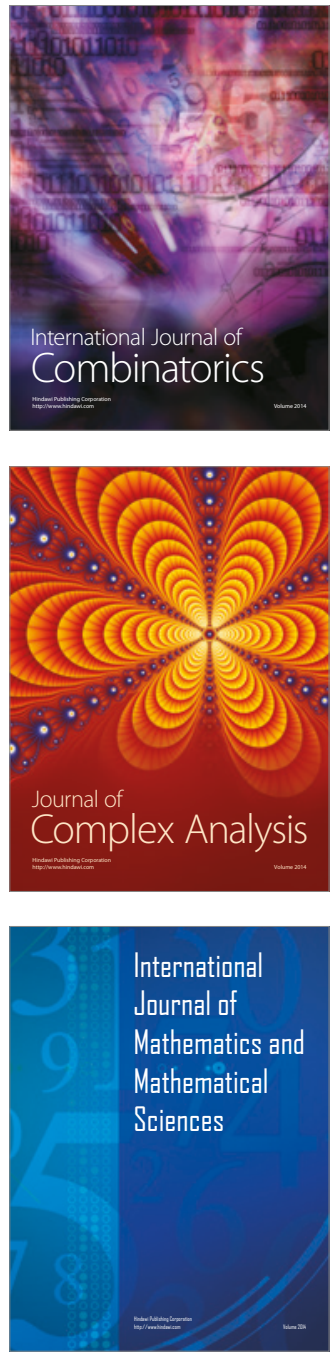
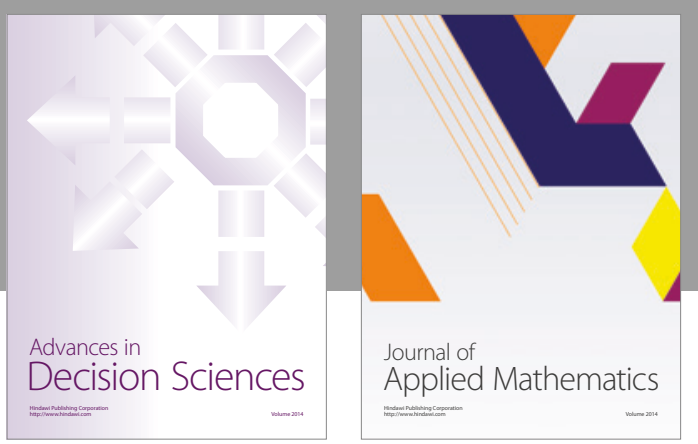

Algebra

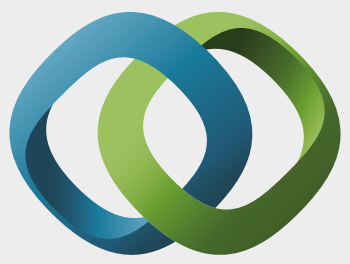

\section{Hindawi}

Submit your manuscripts at

https://www.hindawi.com
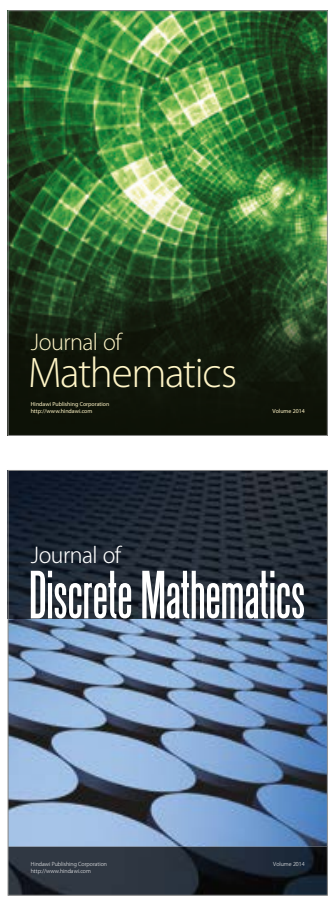

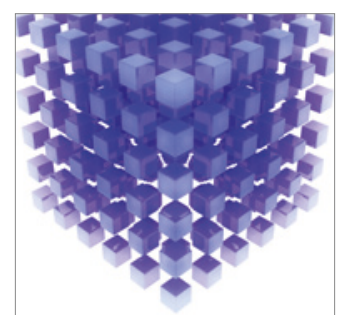

Mathematical Problems in Engineering
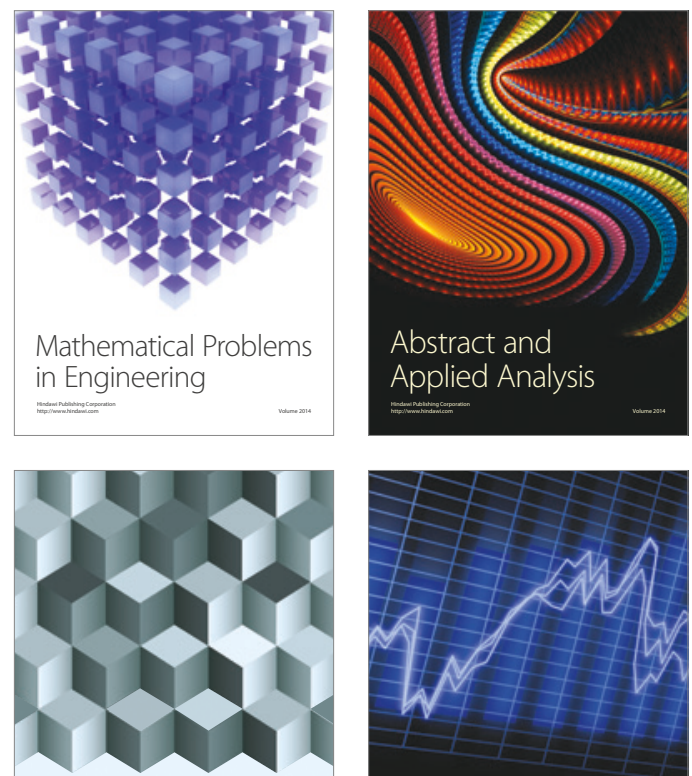

Journal of

Function Spaces

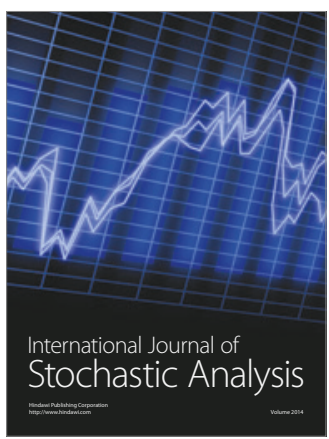

Probability and Statistics
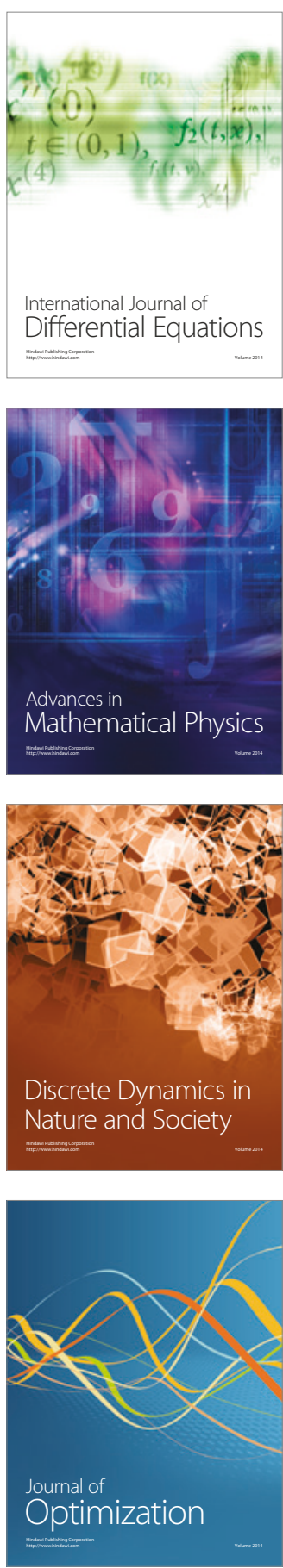